\title{
Sensitivity analysis of the probabilistic damage stability regulations for RoPax vessels
}

\author{
George Simopoulos · Dimitris Konovessis \\ Dracos Vassalos
}

\begin{abstract}
In the light of the newly developed harmonised probabilistic damage stability regulations, set to come into force in 2009, this article presents a systematic and thorough analysis of the sensitivity of the Attained Subdivision Index with reference to a wide range of related design parameters. The sensitivity of the probabilistic regulations was investigated for a typical large RoPax vessel, with variation of parameters, such as the number, positioning and local optimisation of transverse bulkheads; the presence and position of longitudinal bulkheads below the main vehicle deck; the presence of side casings; and the height of the main deck and double bottom. The effects of water on deck and of operational parameters (draught, centre of gravity and trim) were also investigated. The results of the study, presented in graphical form, can provide valuable assistance to the designer when determining subdivision characteristics at the very early stage of the design process, resulting in optimal, efficient and safe ships.
\end{abstract}

Key words Probabilistic damage stability - Sensitivity analysis $\cdot$ Design

\section{Introduction}

The development and implementation of improved damage stability regulations have always been the focus of the international maritime community, especially in the case of passenger ships. For RoPax vessels, the flooding of internal spaces following accidents such as collisions or grounding can result in catastrophic consequences. As tragic accidents have demonstrated in the past, the presence of large undivided spaces for the carriage of vehicles close to the waterline poses the dangers of sinking or rapid capsize with a potentially large number of fatalities among the passengers and crew.

The current damage stability standard is that a RoPax ship should be able to sustain damage to any two adjacent compartments and fulfil a set of deterministic requirements known as SOLAS 90. This represents a significant improvement on the standards applicable at the beginning of the 1990s. In north-west Europe, an increased standard is applied to existing ships, known as the Stockholm Agreement, or SOLAS 90+50, which requires either fulfilment of the deterministic standards of SOLAS 90 with an additional height of water on deck (maximum of $50 \mathrm{~cm}$ ), or the demonstration, by means of model experiments, that the ship can survive, in a damaged condition, the sea state in the area of operation.

Probabilistic damage stability regulations were first adopted by the International Maritime Organisation (IMO) in 1974, when Resolution A.265 (VIII) was introduced as an alternative to the deterministic damage stability regulations for passenger ships. ${ }^{1}$ In 1990, Resolution MSC.19(58) was adopted at the IMO, making the application of a new set of probabilistic damage stability regulations mandatory for all dry cargo ships more than 
$100 \mathrm{~m}$ in length built after February 1992, as detailed in SOLAS, Chapter B-1, Regulation 25. ${ }^{2}$

Research work carried out in the mid-1990s as part of the activities of the Joint North West European Project has resulted in the formulation of an updated framework for damage stability for RoPax ships, providing a number of improvements on the concept. ${ }^{3,4}$ Further research work, carried out as part of the activities of the EC-funded HARDER project, has resulted in a harmonised set of probabilistic rules for all ship types. ${ }^{5,6}$ This latter work has resulted in the adoption at IMO of the new harmonised probabilistic rules for damage stability, due to enter into force in 2009 , for all ship types.

This article presents a systematic investigation of the robustness and sensitivity of the probabilistic damage stability regulations. A typical large RoPax vessel was used as the basis for the variation of a wide range of related design parameters. The results of the analysis are presented in a number of graphs, which can provide valuable guidance to a designer when applying the probabilistic damage stability regulations at the early stages of design.

\section{Robustness of the probabilistic regulations}

To test the sensitivity of the attained Index of Subdivision A, a modern large RoPax vessel was used; it is referred to as PRR1 for the purposes of the study. The ship's main particulars are presented in Table 1 and the hull form is shown in Fig. 1.

The investigation comprises damage stability calculations on two models of PRR1, the model details being the following:

- The first model is a simplified (coarse) model of PRR1, called S1. The vessel is subdivided by transverse bulkheads only in 17 damage zones. No tanks or appendices (e.g., bossing, shafts and rudders) are modelled. Figure 2 illustrates this model.

Table 1. Main particulars of RoPax vessel PRR1

\begin{tabular}{llc}
\hline Length overall & (m) & 194.30 \\
Length B.P. & (m) & 170.00 \\
Subdivision length & (m) & 178.75 \\
Breadth & (m) & 27.80 \\
Depth to vehicle deck & (m) & 9.00 \\
Depth to top deck & (m) & 14.85 \\
Service draught & (m) & 6.25 \\
Displacement (even keel) & (tonne) & 17301.7 \\
Centre of gravity & (m) & 12.892 \\
\hline
\end{tabular}

- The second model of PRR1, called S2, is the actual ship arrangement without any simplifications made. The damage zones and the main transverse bulkheads are the same as in model S1, but all tanks, casings and appendices are considered. Figure 3 illustrates this model.

Table 2 contains a summary of the results for models S1 and S2. The results indicate that the simplified (coarse) model, subdivided only by transverse bulkheads below

Fig. 1. Hull form of RoPax vessel PRR1
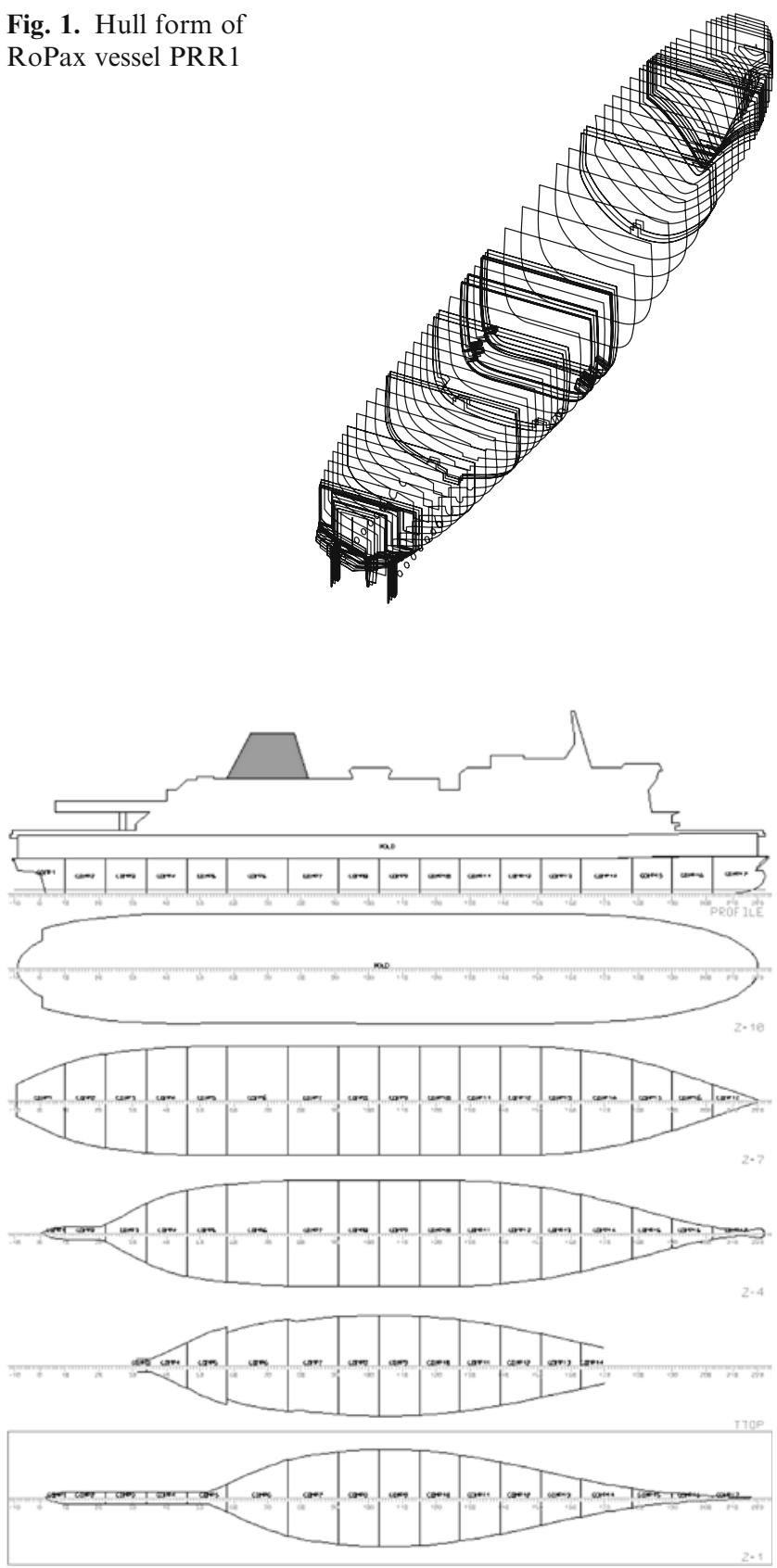

Fig. 2. Model S1-simplified (coarse) model of RoPax vessel PRR1 


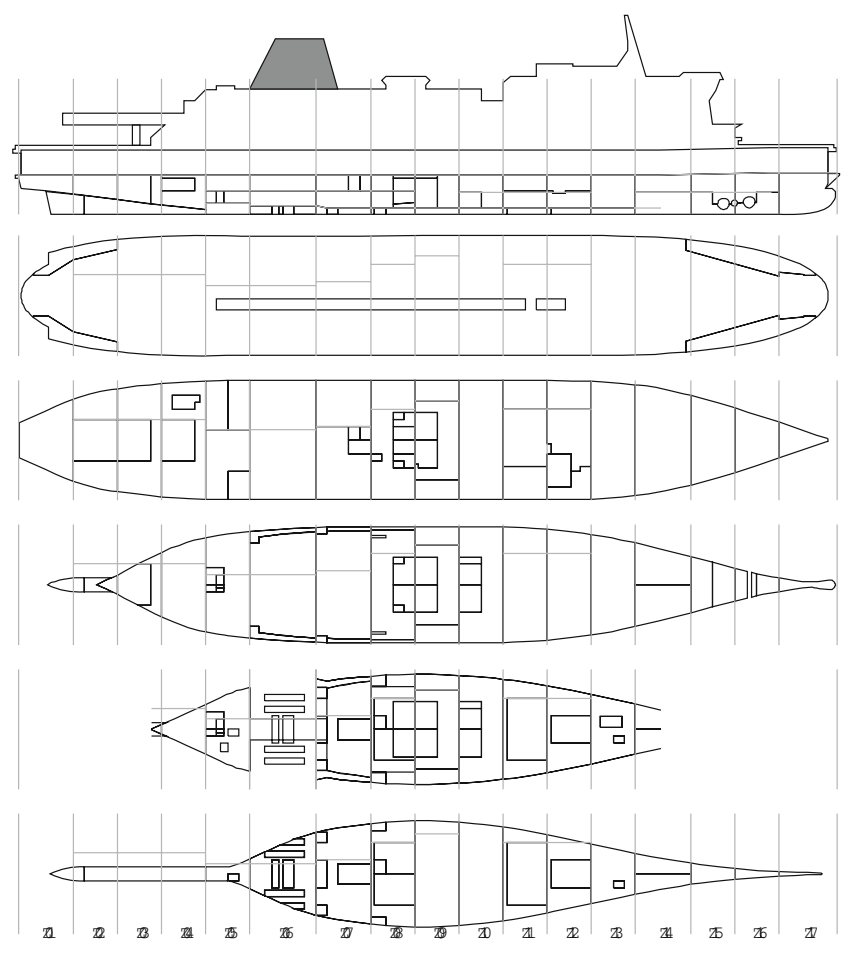

Fig. 3. Model S2 - actual model of RoPax vessel PRR1

Table 2. Probabilistic damage stability calculations for PRR1

\begin{tabular}{lll}
\hline Damage zones & Model S1 & Model S2 \\
\hline Zone 1 damage & 0.26974 & 0.26974 \\
Zone 2 damage & 0.35579 & 0.35419 \\
Zone 3 damage & 0.20873 & 0.20623 \\
Zone 4 damage & 0.07793 & 0.07505 \\
Zone 5 damage & 0.01308 & 0.01191 \\
Index A total & 0.92527 & 0.91712 \\
\hline
\end{tabular}

the main vehicle deck, gives a very accurate value for Subdivision Index A compared with the Index A value of the actual vessel. The difference is $0.89 \%$, a result that gives a designer the opportunity to estimate Index A in the early design phase using a simplified model.

It is thus possible to calculate Index A with good accuracy without having to define all the compartments and tanks of a vessel; fuel tanks and smaller compartments do not need to be modelled to calculate a reasonably accurate value. The reason for the higher value for Index A calculated through the simplified model is mainly due to asymmetric flooding induced by the presence of several tanks, such as the heeling tanks on RoPax ships. It must also be pointed out that the inclusion of down-flooding points significantly lowers the Index A value.

The goal of the simplified model is to capture the essence of the problem and to help the designer make
Table 3. Design parameters affecting the calculation of Index A

\begin{tabular}{lll}
\hline Group & Symbol & Parameter \\
\hline Group 1 & $\mathrm{L}_{\mathrm{S}}$ & Subdivision length \\
& $\mathrm{B}$ & Breadth \\
& $\mathrm{D}$ & $\begin{array}{l}\text { Depth } \\
\text { Below car deck }\end{array}$ \\
Group 2 & & No. of transverse bulkheads \\
& $\mathrm{i}$ & Longitudinal position of bulkheads, \\
& $\mathrm{x}_{\mathrm{i}}$ & defining each compartment between $\mathrm{x}_{\mathrm{i}}$ \\
& & and $\mathrm{x}_{\mathrm{i}+1}$ \\
& & No. of longitudinal bulkheads \\
& $\left(\mathrm{x}_{\mathrm{i}}, \mathrm{x}_{\mathrm{i}+1}\right)$ & $\begin{array}{l}\text { Longitudinal extent of bulkheads } \\
\text { Penetration (mean transverse distance) }\end{array}$ \\
& $\mathrm{b}_{\mathrm{i}}$ & No. of horizontal bulkheads (decks) \\
& $\mathrm{j}$ & Height of horizontal bulkhead \\
& $\mathrm{Hj}(\mathrm{H})$ & Above car deck \\
& $\left(\mathrm{x}_{\mathrm{i}}, \mathrm{x}_{\mathrm{i}+1}\right)$ & Location extent of casings \\
& $\mathrm{W}_{\mathrm{i}}$ & Width of side or central casings \\
& $\mathrm{T}$ & Draught \\
& & KG \\
& & Trim \\
Group 3 &
\end{tabular}

decisions in the early phase of design. The probabilistic regulations can be formulated in an automatic way, focusing on simplifications and optimisation of the subdivision of RoPax ships. Thus, Index A can be calculated using a simplified model, which can significantly reduce the computation time compared to a full model calculation.

\section{Design parameters affecting Subdivision Index A}

The design parameters that can affect the calculation of Index A may be divided in three groups. The first group includes the general geometric parameters, the second group refers to subdivision parameters (internal compartmentation of the hull) and the third group includes the operational parameters that characterise different loading conditions. An overview of these parameters is given in Table 3.

The sensitivity analysis carried out covers systematic variation of the parameters in Groups 2 and 3 on the simplified (coarse) model of the vessel PRR1. Parameter variation was taken one at a time, as follows:

- equidistant transverse bulkheads

- transverse bulkheads: positioning and local optimisation

- longitudinal bulkheads: below the main vehicle deck

- side casings on the main vehicle deck

- main deck and double bottom

- effect of water on deck

- operational parameters 


\section{Equidistant transverse bulkheads}

In this section, results for Index A investigated with respect to compartment layout are presented. Equidistant transverse bulkheads are used with the exception of the aftermost and foremost compartments. The aftermost and foremost compartments (compartments 1 and 17 in Fig. 2) are fixed and several arrangements, varying the number of compartments, are used to examine the sensitivity of Index A. The number of compartments is increased beyond the practical range in order to illustrate more clearly the expected asymptotic behaviour of Index A. All results are shown in Figs. 4-6.

Figure 4 shows the contributions to Index A when the number of adjacent compartments damaged ranged from up to four to up to nine. Figure 5 shows the Index A values based on the number of compartments. Figure 6 shows the additional (differential) contribution to Index $\mathrm{A}$ if a new arrangement were to be selected with one additional equidistant bulkhead. The sharp maximum observed on Figure 6 at 10-12 bulkheads means that one

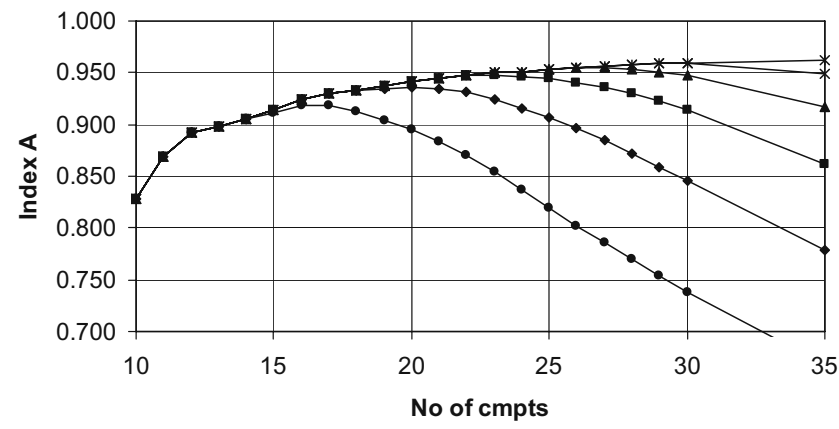

Fig. 4. Sensitivity of Index A to the total number of compartments with equidistant bulkheads when a number of adjacent compartments are damaged. Number of compartments damaged: circles, up to four; diamonds, up to five; squares, up to six; triangles, up to seven; crosses, up to eight; asterisks, up to nine

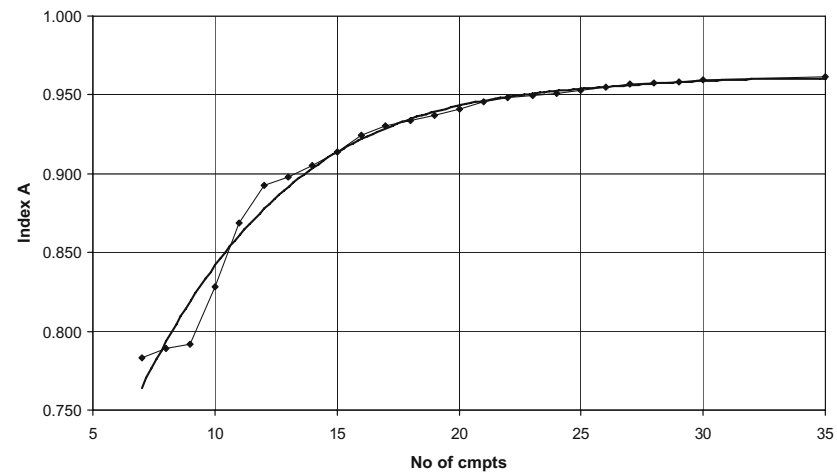

Fig. 5. Index A variation with respect to the total number of compartments with equidistant bulkheads. Data points and a regression line are shown. cmpts, compartments additional bulkhead provides a considerable increase in Index A. It also shows that increasing the number of transverse bulkheads above 20 has no practical effect on Index A.

Further investigations on the effects of the number of compartments on Index A were conducted using two additional RoPax vessels, as shown in Table 4. All the results are presented in Fig. 7.

\section{Transverse bulkheads: positioning and local optimisation}

In the original compartment layout of 17 damage zones, the compartments have the same length of $9.60 \mathrm{~m}$, with the exception of compartments $1(12 \mathrm{~m}), 6(14.40 \mathrm{~m}), 7$ $(12 \mathrm{~m}), 14(12 \mathrm{~m})$ and $17(12.65 \mathrm{~m})$. The longest compartment is compartment 6 , which is the engine room.

In order to optimise the compartment layout, a selection of bulkheads to be shifted is needed. The concept of Local Indices $A_{i}$ is used ${ }^{8}$ as the criterion of selecting a suitable bulkhead, which can be expressed as follows:

$$
\mathrm{A}_{\mathrm{i}}=\frac{\sum a_{i} \cdot p_{i} \cdot s_{i}}{\sum a_{i} \cdot p_{i}}
$$

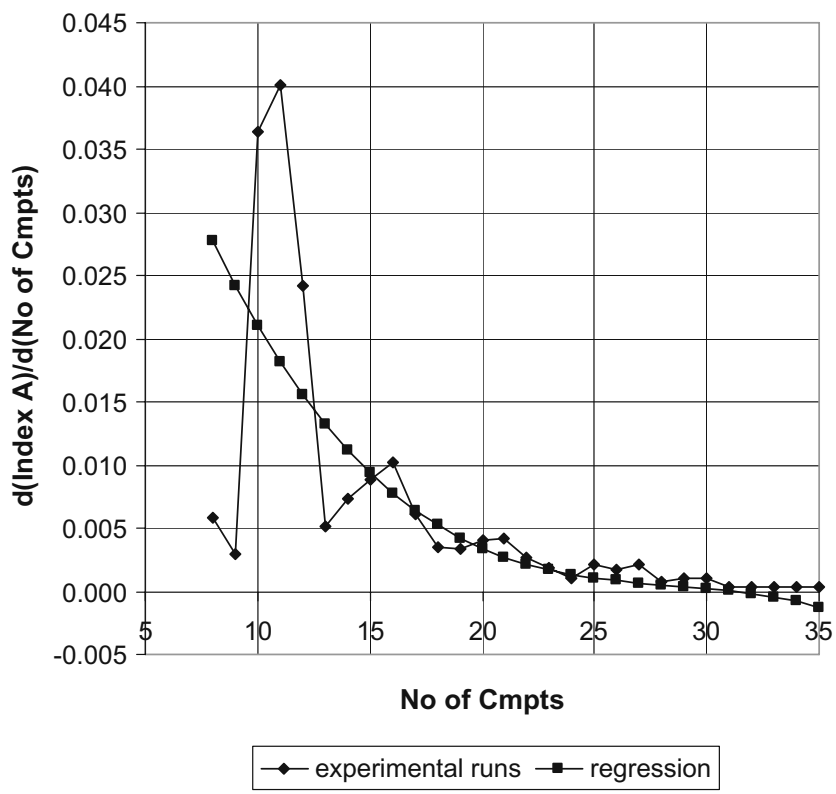

Fig. 6. Increase in Index A resulting from the addition of one extra equidistant bulkhead

Table 4. Main particulars of two additional RoPax vessels

\begin{tabular}{lrr}
\hline & Ship 1 & Ship 2 \\
\hline Ls (m) & 165.33 & 153.40 \\
B (m) & 27.60 & 24.20 \\
T (m) & 6.50 & 5.80 \\
\hline
\end{tabular}




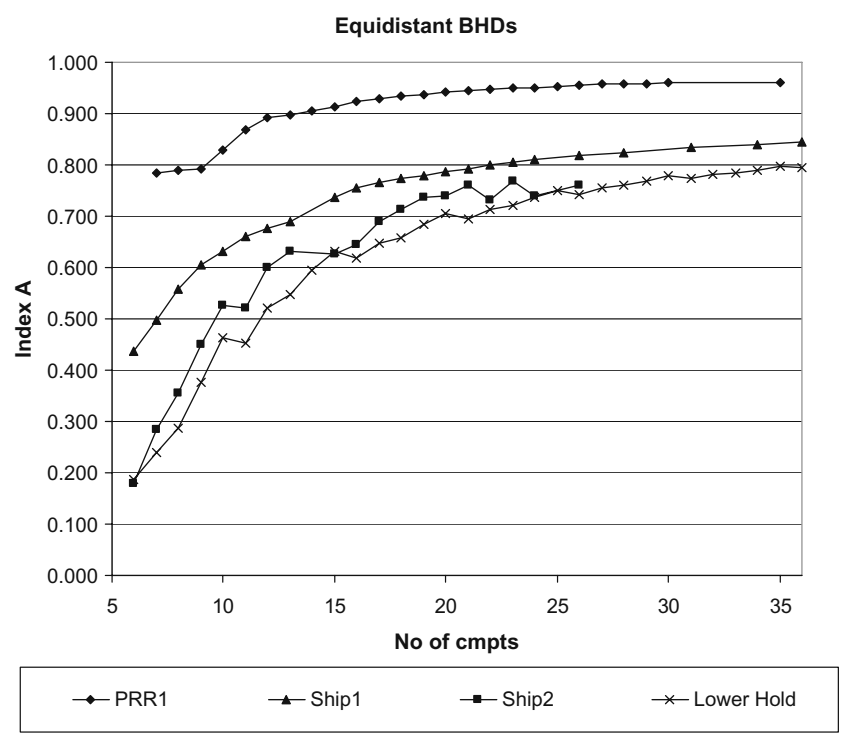

Fig. 7. Index A variation with respect to the number of compartments with equidistant bulkheads for different ship models

Table 5. Local indices $A_{i}$ for single compartment damage

\begin{tabular}{llllllll}
\hline A1 & 0.97307 & A5 & 0.80381 & A9 & 0.89041 & A13 & 0.81733 \\
A2 & 0.93518 & A6 & 0.82738 & A10 & 0.87874 & A14 & 0.86323 \\
A3 & 0.88782 & A7 & 0.86915 & A11 & 0.84785 & A15 & 0.91642 \\
A4 & 0.83191 & A8 & 0.89452 & A12 & 0.81611 & A16 & 0.95419 \\
& & & & & & A17 & 0.98498
\end{tabular}

$a_{i}$, weighting factor for different loading conditions considered; $p_{i}$, probability that only the compartment(s) under consideration are flooded; $s_{i}$, resultant probability of surviving a specific damage scenario.

This index can be calculated for each compartment and represents the survivability contribution of all possible damage modes involving the compartment in question. It might be expected that a uniform distribution of $\mathrm{A}_{1}$ for compartments or groups of adjacent compartments along the ship length would represent an efficient distribution of bulkheads since such an arrangement represents a uniform distribution of survival capability. The results of calculations of Local Indices $A_{i}$ for the case of damage to a single compartment are shown in Table 5 and Fig. 8.

The distribution of the Local Indices $A_{i}$ along the ship's length (Fig. 8) shows a peak in the midship region. This seems to be rather counterintuitive from a stability point of view, since stability following damage is expected to be worst after damage in the midship region. For this reason, a damage survivability investigation was conducted for single- and double-compartment damage using the static equivalent method (SEM). ${ }^{9}$ The results of this investigation are shown in Figs. 9 and 10.

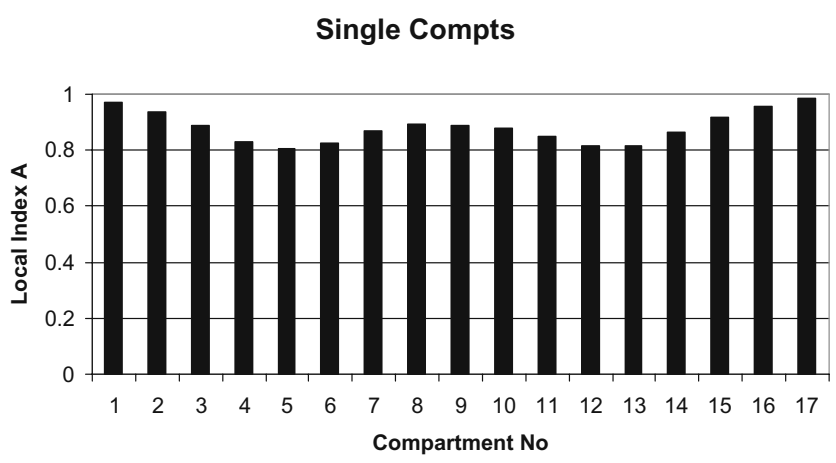

Fig. 8. Local Index A along the vessel's length for damage to each single compartment in turn

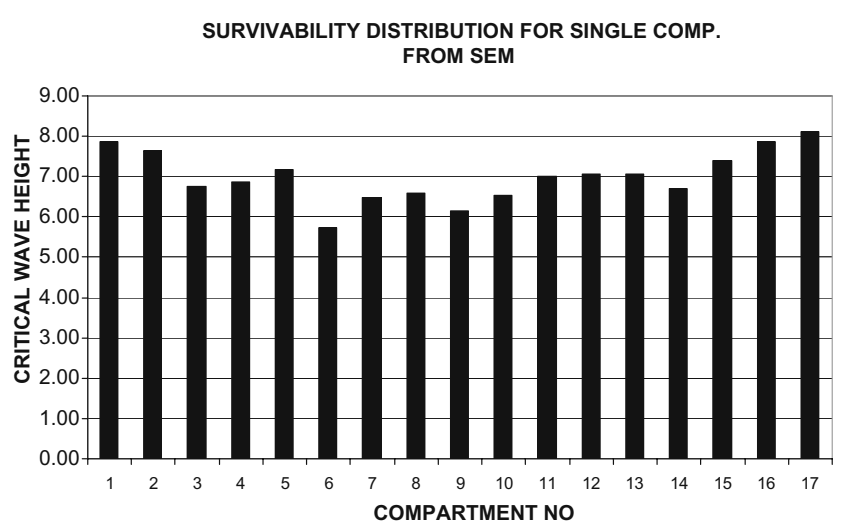

Fig. 9. Critical wave height distribution for damage to each single compartment in turn

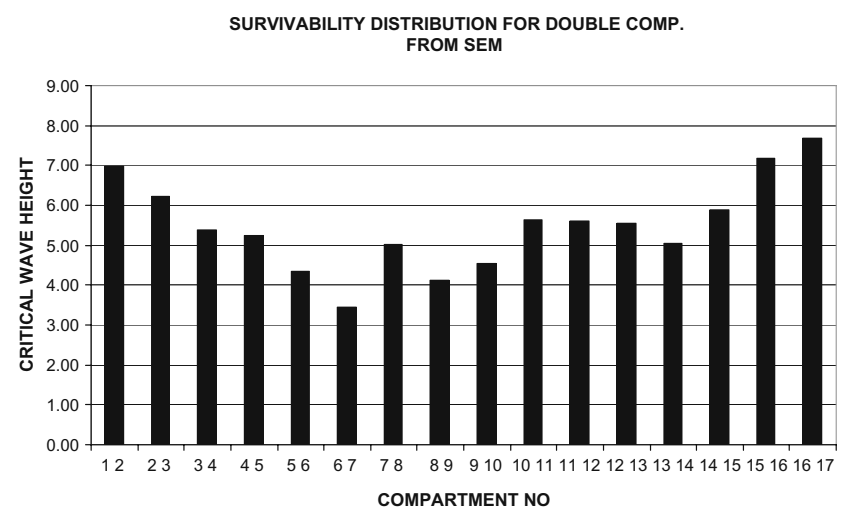

Fig. 10. Critical wave height distribution for damage to two adjacent compartments

Table 6. Loading conditions for vessel PRR1

\begin{tabular}{|c|c|c|c|c|c|}
\hline $\begin{array}{l}\text { Loading } \\
\text { conditions }\end{array}$ & $\begin{array}{l}\text { Draught } \\
\text { (m) }\end{array}$ & Trim & $\mathrm{KG}_{0}(\mathrm{~m})$ & $\mathrm{KG}_{1}(\mathrm{~m})$ & $\mathrm{KG}_{2}(\mathrm{~m})$ \\
\hline Full & 6.25 & 0 & 12.89 & 14.5 & 14.9 \\
\hline Partial & 5.61 & 0 & 13.6 & 15.2 & 15.6 \\
\hline
\end{tabular}


To investigate the sensitivity of Index A with respect to local compartmentation, two sets of loading conditions were selected, as shown in Table 6 . Since the initial conditions gave very high Index A values, the selection was made to allow the examination of conditions with higher centre of gravity values. The results are presented in Figs. 11 and 12. Zero on the horizontal axis of these figures refers to the original position of bulkhead 4 (the aft bulkhead of the engine room); 100 means that bulkhead 4 is shifted to the location of bulkhead 5 . The curves notated as "fixed s" were derived by calculating the required "s" factors only for the original location of the relevant transverse bulkhead. In this case, on the repositioning of the bulkhead, the "s" factors remained fixed and no new calculations were performed.

\section{Longitudinal bulkheads below the main vehicle deck}

This section refers to the investigation of Index A in terms of the positioning of longitudinal bulkheads below

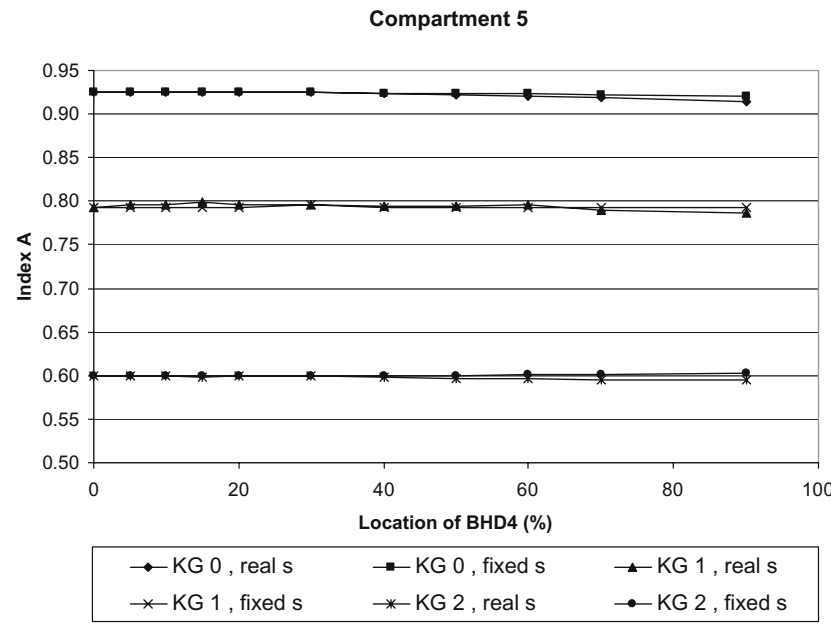

Fig. 11. Sensitivity of Index A to shifting bulkhead 4 (BHD 4) with respect to $\mathrm{KG}$ and s factor. Position $0 \%$ is the original position of bulkhead 4 and $100 \%$ means that bulkhead 4 has been moved to the position of bulkhead 5 the main vehicle deck with respect to compartment configuration and to cross-connection of the wing tanks. For these investigations, the simplified (coarse) model of PRR1 was used. The selected configurations for investi-

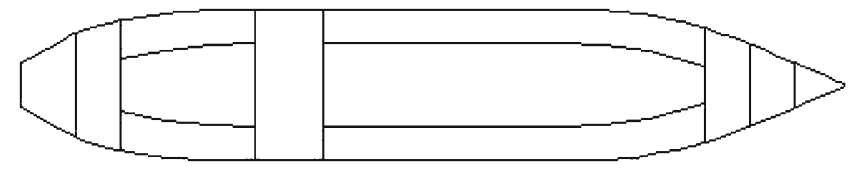

Fig. 13. Configuration L0

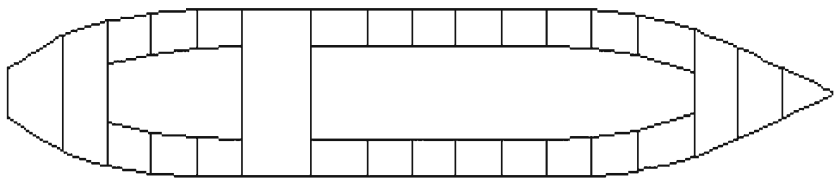

Fig. 14. Configuration L1

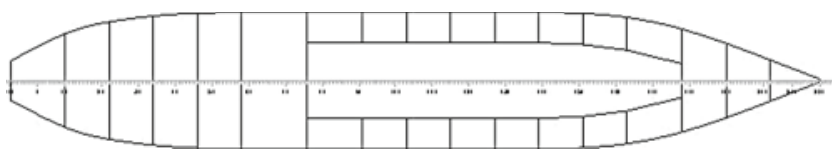

Fig. 15. Configuration L2

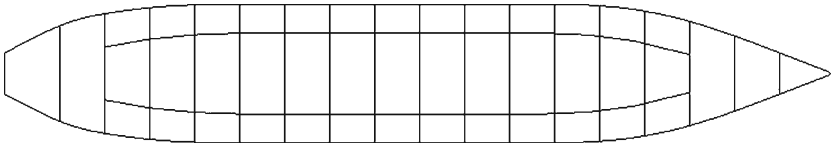

Fig. 16. Configuration L3

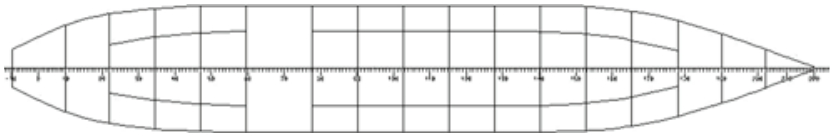

Fig. 17. Configuration L4

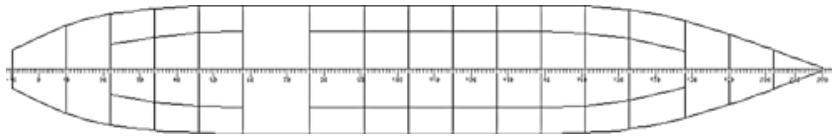

Fig. 18. Configuration L5
Fig. 12. Sensitivity of Index A to shifting bulkhead 4 with respect to $\mathrm{s}$ factor. The graphs show detailed views of the upper and lower lines in Fig. 11
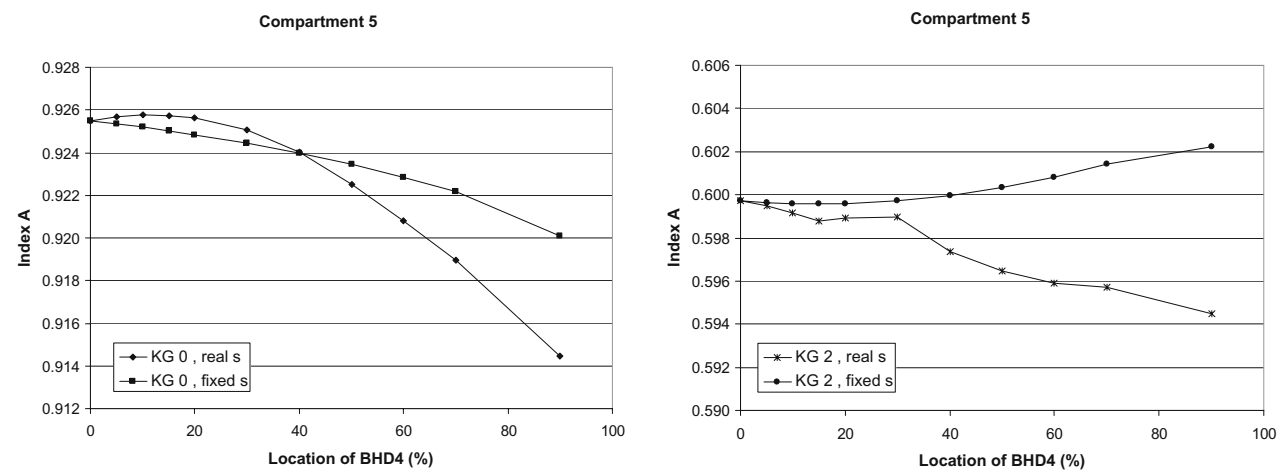
gation are designated L0, L1, L2, L3, L4 and L5, and are shown on Figs. 13-18.

Configuration LO (Fig. 13). Compared with the coarse model configuration, L0 keeps compartments 1, 2, 6, 15, 16 and 17 fixed (that is the first two and the last three compartments as well as the engine room). Two large open spaces are formed and subdivided only by two symmetrical longitudinal bulkheads. This is an unrealistic configuration; however, investigation was carried out to examine the sensitivity of Index A to the existence and position of longitudinal bulkheads.

Configuration L1 (Fig. 14). The only difference between configurations $\mathrm{L} 0$ and $\mathrm{L} 1$ is that in $\mathrm{L} 1$ the wing tanks, formed by the longitudinal bulkheads, are subdivided by transverse bulkheads at the same positions as in the subdivision of the coarse model. The investigation examines the sensitivity of Index A to the existence and position of longitudinal bulkheads.

Configuration L2 (Fig. 15). This configuration is the same as the coarse model from compartment 1 (aft peak) up to compartment 6 (the engine room), and then from compartment 7 to compartment 17 (fore peak) it is the same as configuration L1. The investigation examines the sensitivity of Index A to the existence and position of longitudinal bulkheads.

Configuration L3 (Fig. 16). Compared with the configuration of the coarse model, L3 has compartments 1, 2, 15, 16 and 17 fixed (that is the first two and the last three compartments). A large open space is formed and subdivided by equidistant transverse bulkheads and by two symmetrical $\mathrm{B} / 5$ longitudinal bulkheads. The investigation examines the sensitivity of Index A to the number of compartments (number of equidistant compartments plus the five fixed compartments).

Configuration L4 (Fig. 17). The only difference between configurations L3 and L4 is that in L4 the length of the engine room is fixed and is the same as the length of the engine room in the coarse model. The position of the engine room is not fixed but it is located near the original position of the coarse model and according to the length of the equidistant compartments. The investigation examines the sensitivity of Index A to the number of compartments (number of equidistant compartments plus the six fixed compartments).

Configuration L5 (Fig. 18). In addition to the coarse model subdivision, two symmetrical longitudinal bulkheads subdivide the vessel except for the first two and the last three compartments and the engine room compartment. The investigation examines the sensitivity of Index $\mathrm{A}$ to the existence and positioning of longitudinal bulkheads.

The configurations considered are designated LxyC, with $\mathrm{x}$ taking the values $0,1,2,3,4$ or 5 (denoting the configuration under examination) and $\mathrm{y}$ is either $\mathrm{N}$ or $\mathrm{C}$; $\mathrm{C}$ indicates that the wing tanks are cross-connected and $\mathrm{C}$ indicates that there is no cross-connection of the wing tanks.

The main initial condition, shown in Table 1, is designated $\mathrm{R}$. Knowing that condition $\mathrm{R}$ gives very high Index A values, some supplementary operational conditions have been selected in order to obtain lower Index A values and hence provide a sufficient margin for optimisation.

Having as a base the $\mathrm{R}$ condition, the increased $\mathrm{KG}$ (incr-KG) conditions refer to fixed draught and trim, whilst the increased draught (incr-T) conditions refer to fixed $\mathrm{KG}$ and trim. Condition D refers to fixed trim (at even keel) and is at the same draught as the incr-T condition. KG values derive from the relevant graph of permissible KGmax values with respect to draught. All the conditions used in the investigations are presented in Table 7.

All six compartmentation configurations were investigated with respect to wing tank cross-connection, the position of longitudinal bulkheads and the number of compartments below the main vehicle deck. The results derived from this investigation of the usage of longitudinal bulkheads below the car deck are presented in Figs. 19-25.

Figures 19 and 20 show the sensitivity of Index A to changes in the longitudinal bulkhead position with respect to configurations L0, L1 and L2 and also with respect to wing tank cross-connection. Figures 21-24 show the sensitivity of Index A to changes in the number of compartments below the main vehicle deck with respect to configurations L 3 and L4 and also with respect to wing tank cross-connection. The curves without the cross-connection status indicated (e.g., L3, L3-R and L3-D) refer to configurations L3 and L4 without the relevant longitudinal bulkheads. Finally, Fig. 25 shows the sensitivity of Index A to changes in the longitudinal bulkhead positions with respect to configuration L5 and also with respect to wing tank cross-connection.

\section{Side casings on the main vehicle deck}

This section refers to the investigation of Index A in terms of the positioning of side casings on the main vehicle deck. The simplified model of PRR1 is again used 
Table 7. Loading conditions

\begin{tabular}{|c|c|c|c|}
\hline Incr-KG & $\begin{array}{l}\text { T: } 6.25 \text { and } 5.61 \mathrm{~m} \\
\text { Trim }=0 \\
\text { KG: } 14.40 \text { and } 15.20 \mathrm{~m}\end{array}$ & Incr-T & $\begin{array}{l}\text { T: } 6.50 \text { and } 5.76 \mathrm{~m} \\
\text { Trim }=0 \\
\text { KG: } 12.89 \text { and } 13.60 \mathrm{~m}\end{array}$ \\
\hline $\mathrm{R}$ & $\begin{array}{l}\text { T: } 6.25 \text { and } 5.61 \mathrm{~m} \\
\text { Trim }=0 \\
\text { KG: } 12.89 \text { and } 13.60 \mathrm{~m}\end{array}$ & $\mathrm{D}$ & $\begin{array}{l}\text { T: } 6.50 \text { and } 5.76 \mathrm{~m} \\
\text { Trim }=0 \\
\text { KG: } 12.50 \text { and } 13.56 \mathrm{~m}\end{array}$ \\
\hline
\end{tabular}

Fig. 19. Sensitivity of Index A to the position of the longitudinal bulkheads with respect to configurations $\mathrm{L} 0, \mathrm{~L} 1$ and L2 and to whether the wing tanks are cross-connected for conditions $\mathrm{R}$, left, and $\mathrm{D}$, right. On the horizontal axis, $b$ is the distance between the

longitudinal bulkheads and the hull of the vessel. The third character in the configurations (e.g., L0CC-R) is either a C, for wing tanks cross-connected, or $\mathrm{N}$, for not connected

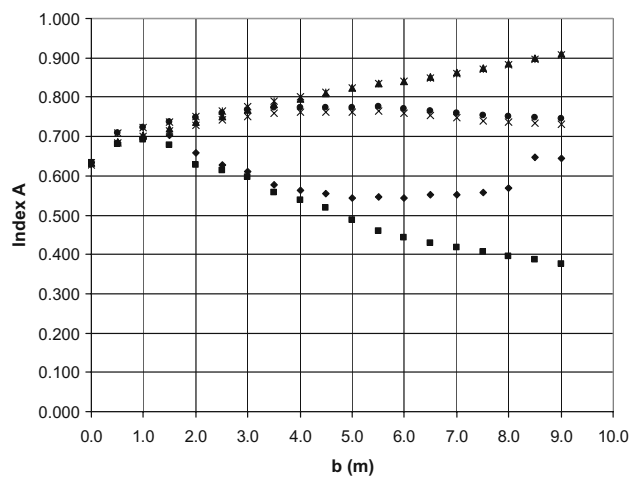

- LOCC-R - LONC-R \L1CC-R $\times$ L1NC-R * L2CC-R • L2NC-R

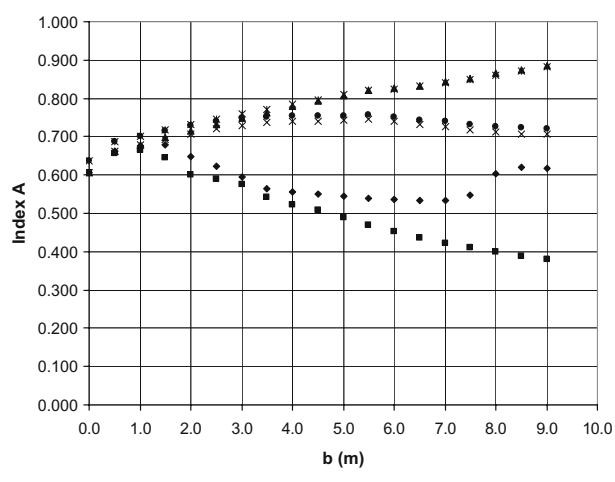

- LOCC-D - LONC-D \ L1CC-D $\times$ L1NC-D $*$ L2CC-D • L2NC-D
Fig. 20. Sensitivity of Index A to the position of longitudinal bulkheads with respect to configurations L0, L1 and L2 and to whether the wing tanks are cross-connected for conditions incr-T, left, and incr-KG, right
Fig. 21. Sensitivity of Index A to the number of compartments below the main vehicle deck with respect to configurations L3 (left), L4 (right) and to wing tank cross-connection (condition $\mathrm{R}$ )
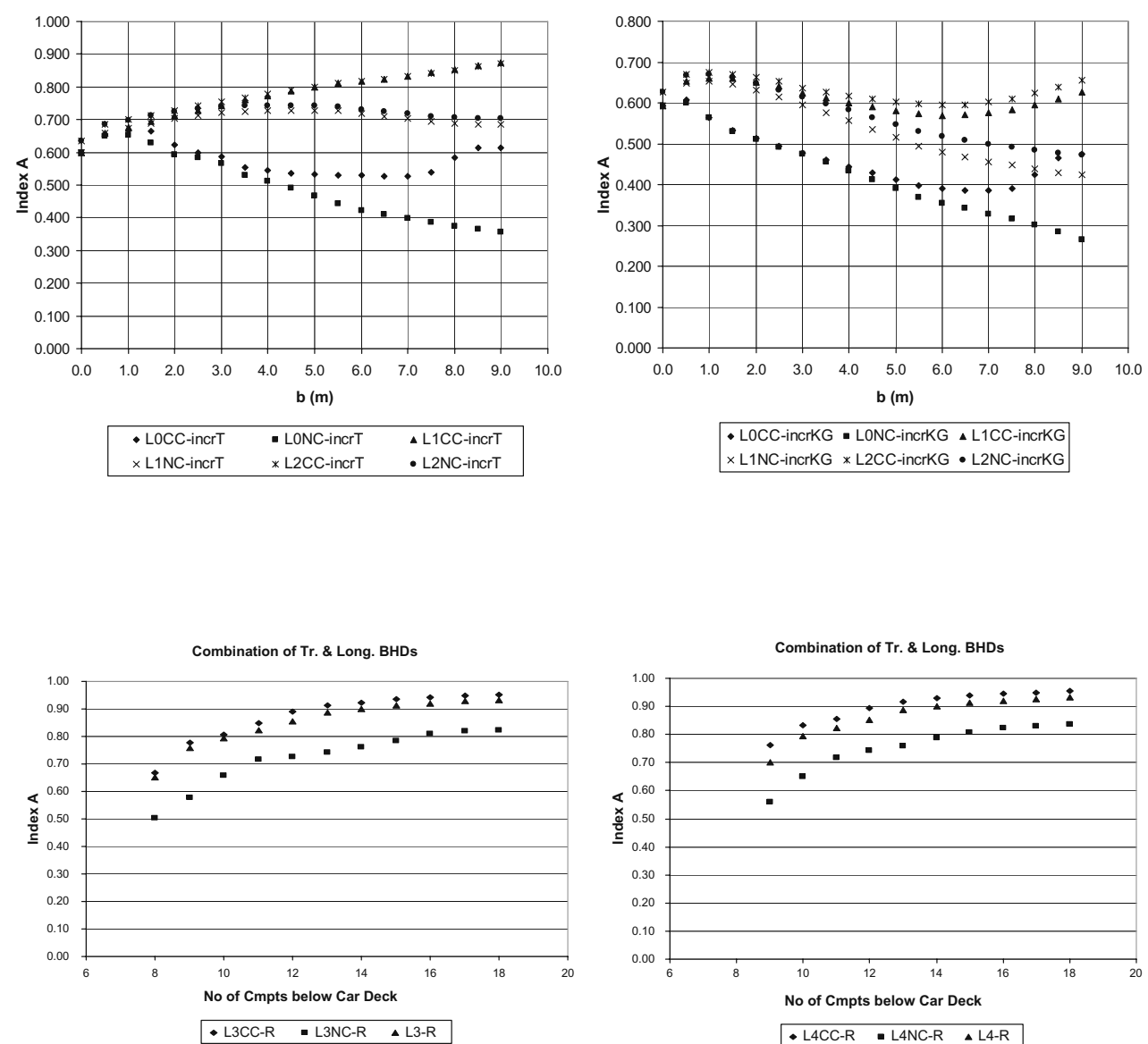
Fig. 22. Sensitivity of Index A to the number of compartments below the main vehicle deck with respect to configurations L3 (left), L4 (right) and to wing tank cross-connection (condition D)

Fig. 23. Sensitivity of Index A to the number of compartments below the main vehicle deck with respect to configurations L3 (left), L4 (right) and to wing tank cross-connection (condition incr-T)

Fig. 24. Sensitivity of Index A to the number of compartments below the main vehicle deck with respect to configurations L3 (left), L4 (right) and to wing tank cross-connection (condition incr-KG)

Fig. 25. Sensitivity of Index A to the position of longitudinal bulkheads with respect to configuration L5 and to wing tank cross-connection [conditions R and D (left) and incr-T and incr-KG (right)]
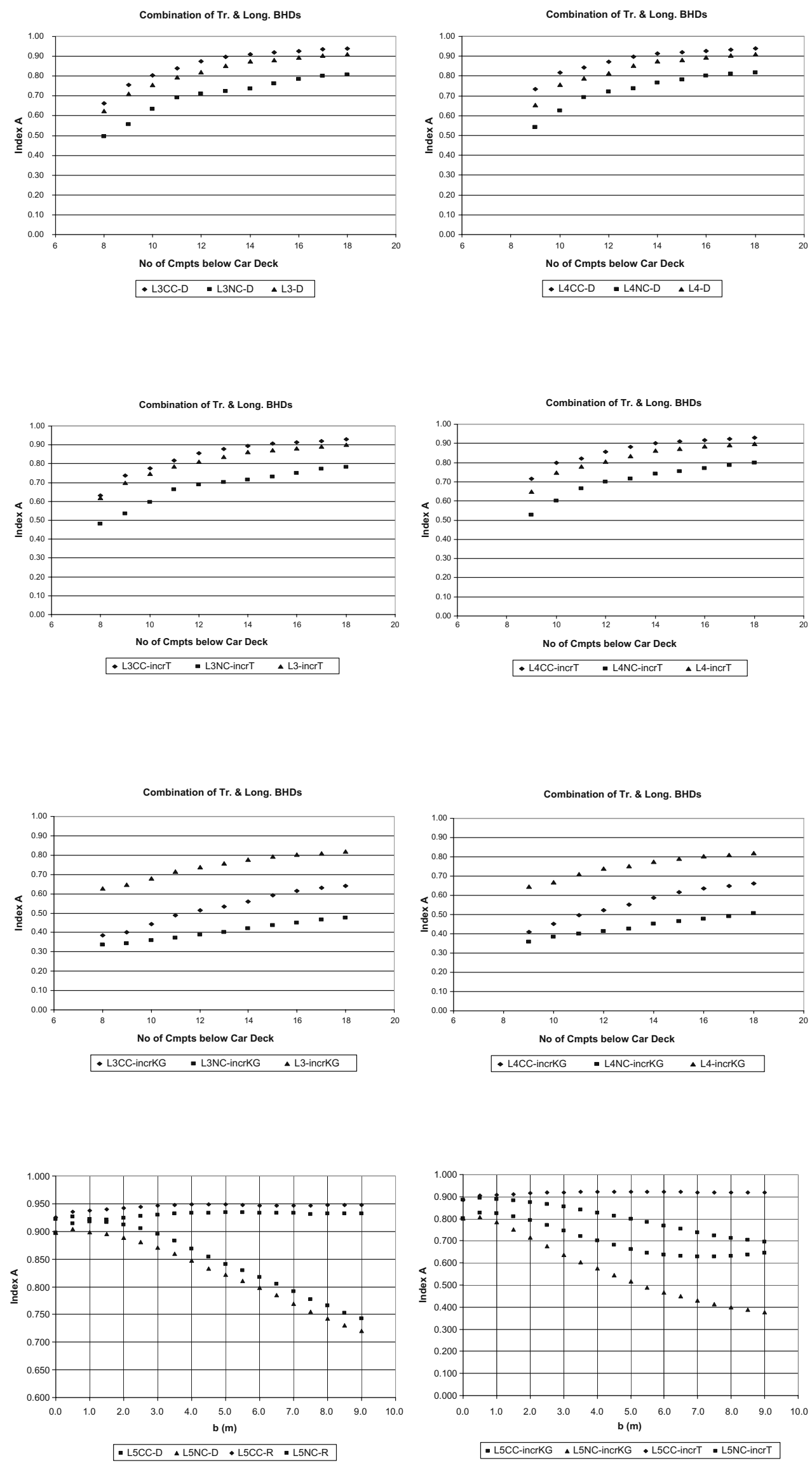
as the basis for the investigation, i.e., the configuration with 17 compartments below the car deck subdivided transversely. The position of the longitudinal bulkheads is examined in the range $0-7 \mathrm{~m}$ as measured from the shell of the hull, thus producing wing tanks with the same width. The transverse bulkheads below the main vehicle deck are extended above the main vehicle deck from compartment 3 to compartment 14 between the shell and the longitudinal bulkheads at either side of the ship, as shown in Fig. 26. The results of the investigation are shown in Fig. 27.

\section{Main vehicle deck and double bottom}

The investigation of Index A in terms of height variation of the main vehicle deck and double bottom is presented in this section. The only difference in the model used for this investigation compared to the simplified model of PRR1 is the inclusion of a double bottom as shown in Fig. 28.

The positions of the vessel's deck and double bottom were varied in the range $\pm 60 \mathrm{~cm}$ in steps of $20 \mathrm{~cm}$. With reference to variation in the double bottom height, the

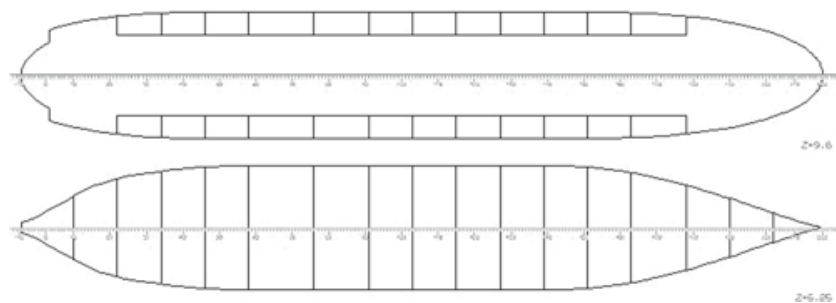

Fig. 26. Configuration with longitudinal bulkheads on the main vehicle deck

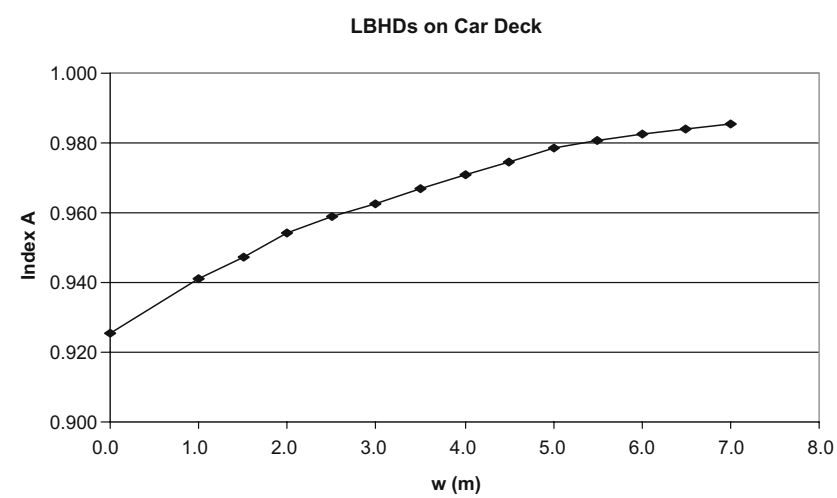

Fig. 27. Sensitivity of Index A to the position of longitudinal bulkheads above the main vehicle deck. $w$, width of the side causing double bottom of the engine room and of all the compartments abaft was kept fixed.

In addition to examination of the height of the decks in this study, the effect of associated $\mathrm{KG}$ variations can provide more realistic results. Therefore, the investigation was first conducted including calculations with fixed $K G$ values, but after that the same scenarios were recalculated with associated $\mathrm{KG}$ variations. As a rough estimation, $\mathrm{KG}$ variations were considered for half of the main vehicle deck variation. All results are shown in Figs. 29 and 30; note that the effect of water on deck was not considered in this section.

\section{Effect of water on deck}

In an attempt to obtain more realistic results for our sensitivity investigations, variations in the position of the main vehicle deck and double bottom were examined again with the additional consideration of the effect of accumulated water on the main vehicle deck. In this respect, the survival factor $\mathrm{s}_{\mathrm{w}}$ is used for damage sce-

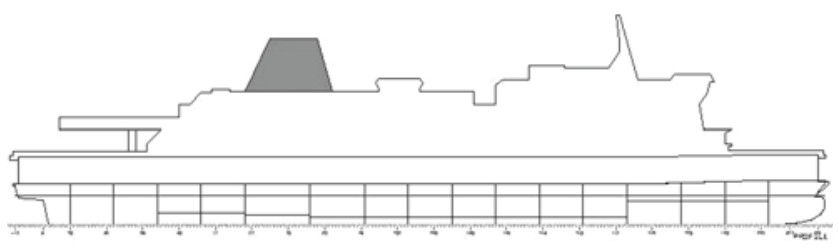

Fig. 28. Configuration with a double bottom

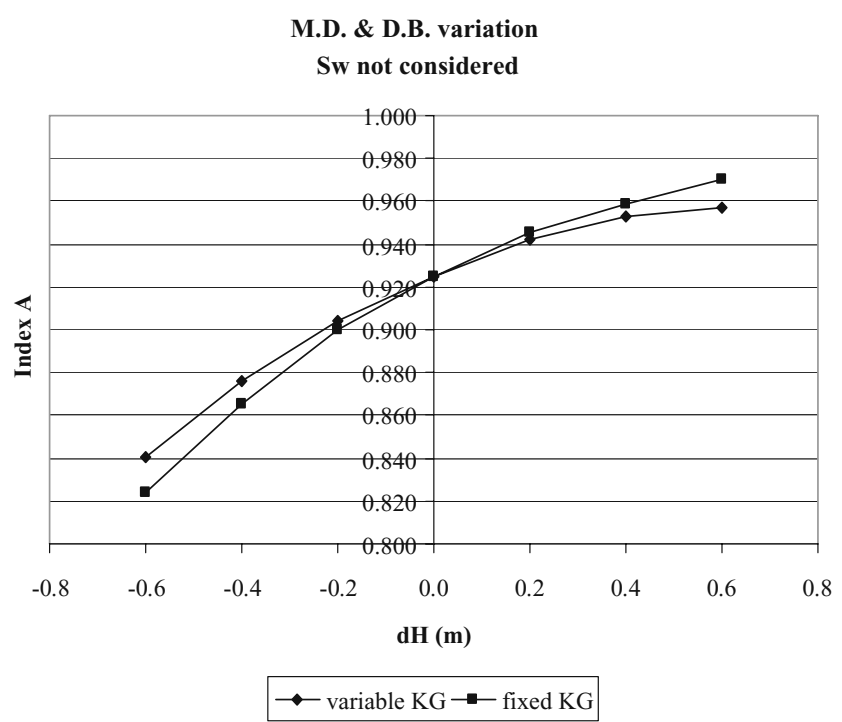

Fig. 29. Sensitivity of Index A to the position of the main vehicle deck and double bottom. Variations are made together, $d H(m)$ is the overall variation. $S w$ not considered, $\mathrm{S}=\mathrm{Sa}$ only 


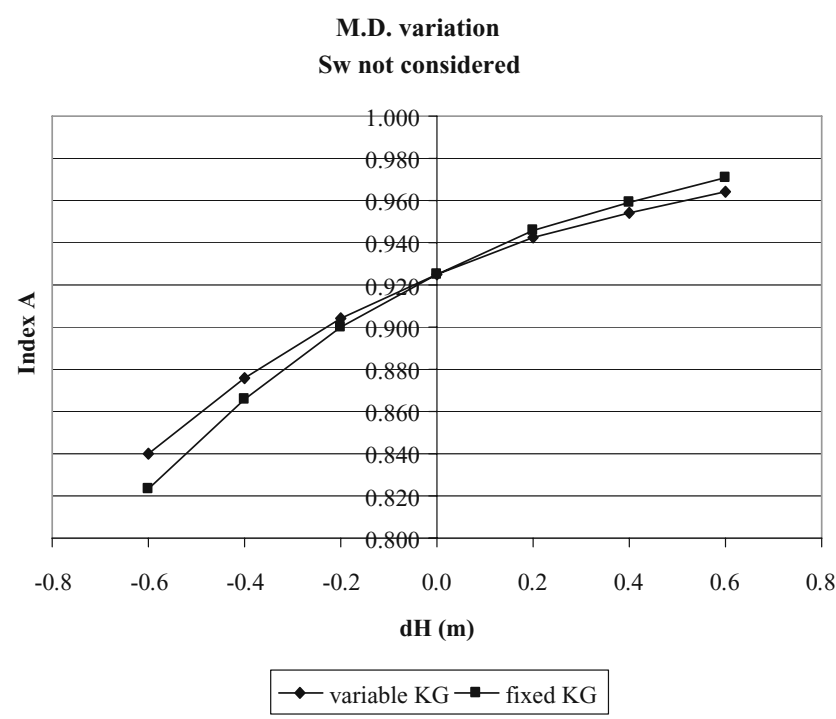

Fig. 30. Sensitivity of Index A to the position of the main vehicle deck

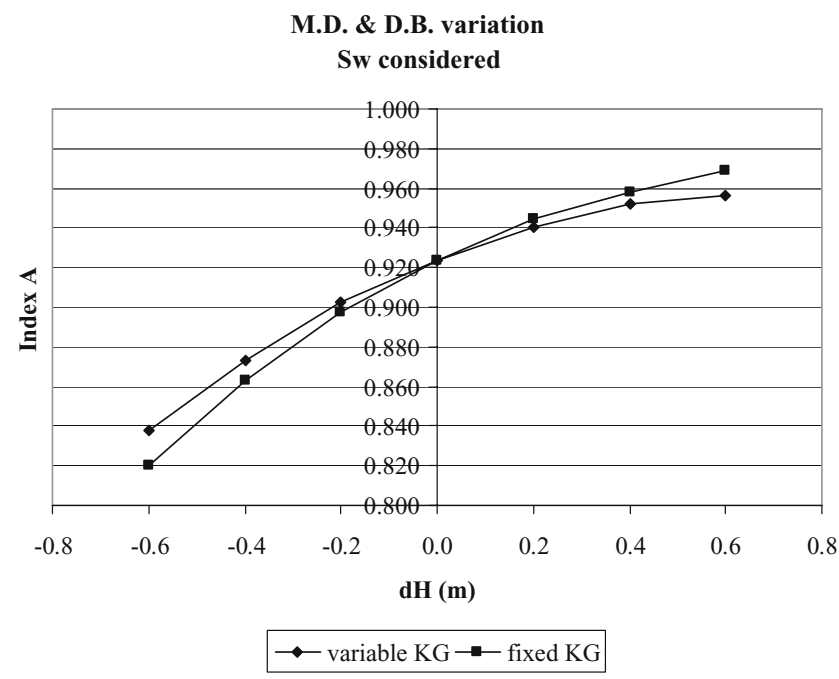

Fig. 31. Sensitivity of Index A to the position of the main vehicle deck and double bottom considering the effect of water on deck

narios in which flooding of the main vehicle deck occurs. The survival factor " $\mathrm{s}$ " for these cases was calculated as ${ }^{10}$ $\mathrm{s}=\mathrm{s}_{\mathrm{a}} \times \mathrm{s}_{\mathrm{w}}$, where the factor $s_{a}$ reflects the probability of the ship surviving pure loss of stability, heeling moments, cargo shift, angle of heel and progressive flooding and the factor $\mathrm{s}_{\mathrm{w}}$ reflects the probability of the ship surviving situations involving accumulation of water on the main vehicle deck as the result of wave action. The latter was calculated using the original SEM formulation, as described in Vassalos et al. ${ }^{9}$

The effects of water on the deck are shown in Fig. 31 for variations in the height of the main vehicle deck and double bottom. Comparisons between fixed and variable $\mathrm{KG}$ values were examined, as explained in the previous section.

\section{Operational parameters}

This section refers to variation of the design parameters in group 3 (see Table 3). It includes investigation of the parameters affecting different loading conditions, i.e., the draught, centre of gravity and trim.

Several loading conditions were examined. As a first phase, 504 runs were carried out in the region near the existing initial conditions from the lightest service to the deepest draught. In order to examine possible additional loading conditions, a further 346 runs were carried out in order to further investigate sensitivity trends of Index A.

\section{Conclusions}

The results of a systematic and thorough investigation of the robustness and sensitivity of the probabilistic damage stability regulations with reference to related design parameters are presented in this article. Very few ships have been designed to date on the basis of the probabilistic subdivision regulations, and the results of this study, even though based on the investigation of one typical large RoPax ship, are therefore of great interest in finding underlying and emerging trends and in helping the designer at the early stages of the ship design process to determine optimal and efficient ship designs. The main conclusions of this study are discussed below.

Variation in the number of transverse bulkheads

The investigation of the sensitivity of Index A with respect to the number of compartments resulted in an asymptotic curve, a result that was anticipated (Figs. 4, 5 and 7). Figure 6 shows the extra contribution to Index A if a new arrangement is selected with one additional equidistant bulkhead. The curve has a peak for layouts with 10 or 11 compartments. For arrangements with more than 21 compartments, the increase in Index A is small. Therefore, there is no reason to examine further the option of using additional transverse bulkheads. However, it is important to select an arrangement with more than 11 compartments, the position of the peak. Overall, an arrangement of 16-20 compartments seems appropriate.

Figure 5 coupled with Fig. 6 can provide an optimum range on the number of compartments below the main 
vehicle deck in the early phase of design by providing an acceptable tolerance for the differential $(\mathrm{dA} / \mathrm{dN})$. Fine tuning can be achieved considering issues such as building cost. Figure 7 shows that a family of regression formulae can be identified in order to estimate Index A according to the number of compartments below the main vehicle deck.

\section{Positioning of transverse bulkheads}

For all layouts examined, maximum and minimum values of the curve of Local Indices $A_{i}$ occur in the same regions. The peaks of the curve are at the aftermost and foremost compartments, as would be expected, since the survival factor for damage scenarios to these compartments equals unity (Fig. 8). Figures 9 and 10 show the critical wave height distribution for single- and doublecompartment damage scenarios obtained by carrying out calculations using the static equivalent method.

The sensitivity analysis carried out demonstrates that this approach can be used to identify the location that would offer the bigger potential benefit when shifting transverse bulkheads. Figure 11 shows that, for a wide range of $\mathrm{KG}$ values, Index A is insensitive to relocation of a single transverse bulkhead. It can thus be deduced, as also shown in Fig. 12, that in the case of repositioning a bulkhead, recalculations of the survival factor can be avoided.

Presence of longitudinal bulkheads

The presence of a lower hold is very convenient and according to Figs. 20 and 21, referring to configurations L1 and L2, proves to be appropriate. When the wing tanks are not cross-connected, the optimum position of longitudinal bulkheads is close to $\mathrm{B} / 5$. However, the cross-connection of wing tanks gives better survival results, especially for $b \geq 4.5 \mathrm{~m}$ ( $\sim 16 \%$ of $\mathrm{B})$.

Figures 22-25 show that for configurations L3 and L4 (combinations of transverse and longitudinal bulkheads), the sensitivity of Index A to the number of compartments results in an asymptotic pattern. Figures 21-23 and 25 also show that wing tank cross-connection is strongly recommended in this case. Otherwise, it can be recommended not to use longitudinal bulkheads at all and to opt for a simpler configuration of transverse subdivision only.

Referring to Fig. 25, configuration L5 (combined transverse and longitudinal bulkheads), when compared with the coarse model of PRR1 $(b=0)$, does not result in a great improvement of the value of Index A; thus, in this case, the use of pure transverse subdivision is sufficient.

Side casings on the main vehicle deck. Figure 27 shows that the existence of side casings on the car deck has a great impact on Index A.

Variation of main vehicle deck height. Figures 29 and 30 show that increases in the vessel's depth result in higher values of Index A. Considering the associated KG variation, the slope of the curve decreases as the vessel's depth increases, having as the intersection point the original configuration. Figures 29 and 30 also indicate that Index A is rather insensitive to variations in the double bottom height.

Effect of water on deck. Figure 31 shows that the effect of water on deck results in lower Index A values, especially at the lower range of main vehicle deck heights considered.

Variation of operational parameters. Figures 32-36 verify that increases in the draught or in the vertical centre of gravity result in a decrease in the value of Index A. Figure 32 shows that there is a critical value for the centre of gravity for every fixed-draught curve beyond which Index A decreases dramatically. Overall, Index A is sensitive to variations in the draught and centre of gravity but rather insensitive to variations in the trim,
Fig. 32. Sensitivity of Index A to the centre of gravity with respect to draught. Left, draught variation 11.5 to $15.5 \mathrm{~m}$; right, 11 to $18 \mathrm{~m}$
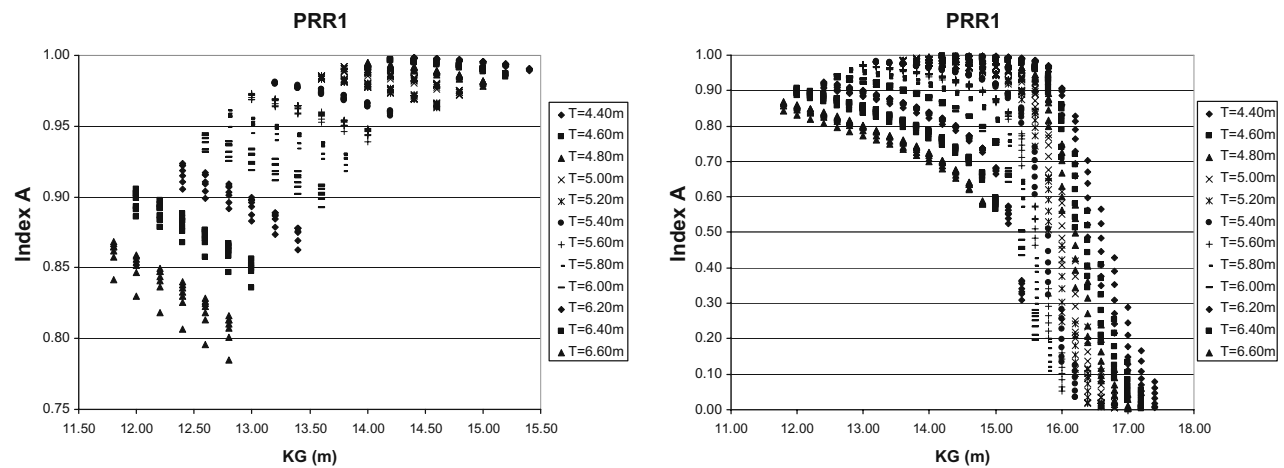


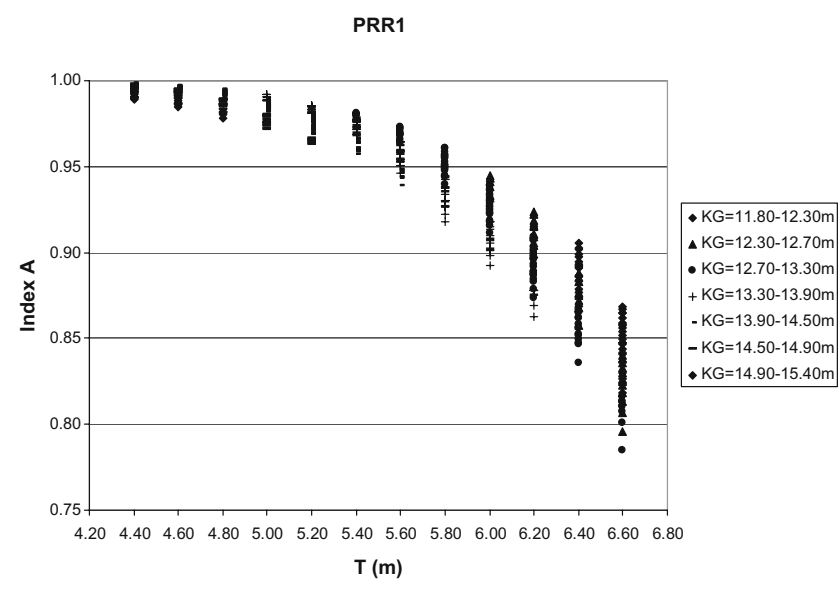

Fig. 33. Sensitivity of Index A to the draught with respect to the centre of gravity

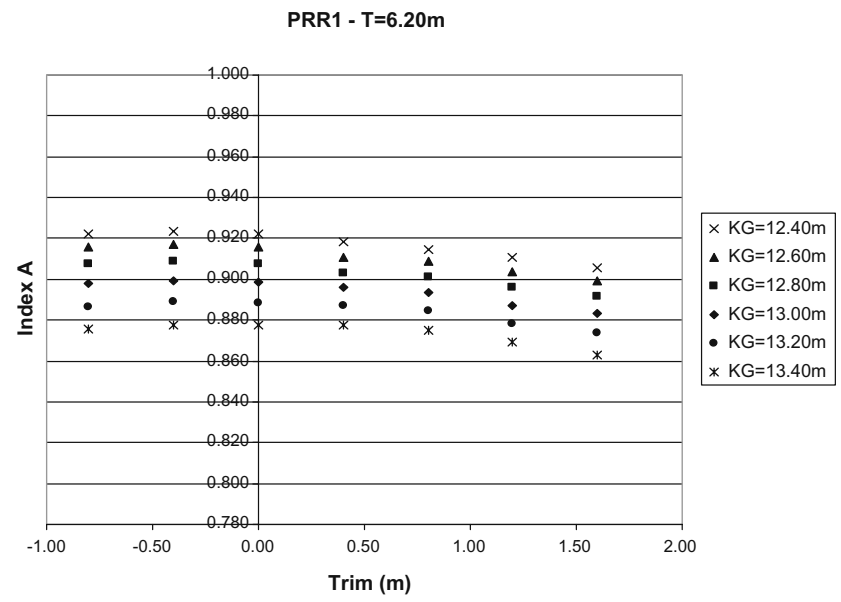

Fig. 34. Sensitivity of Index A to the trim with respect to the centre of gravity. The draught is $6.20 \mathrm{~m}$

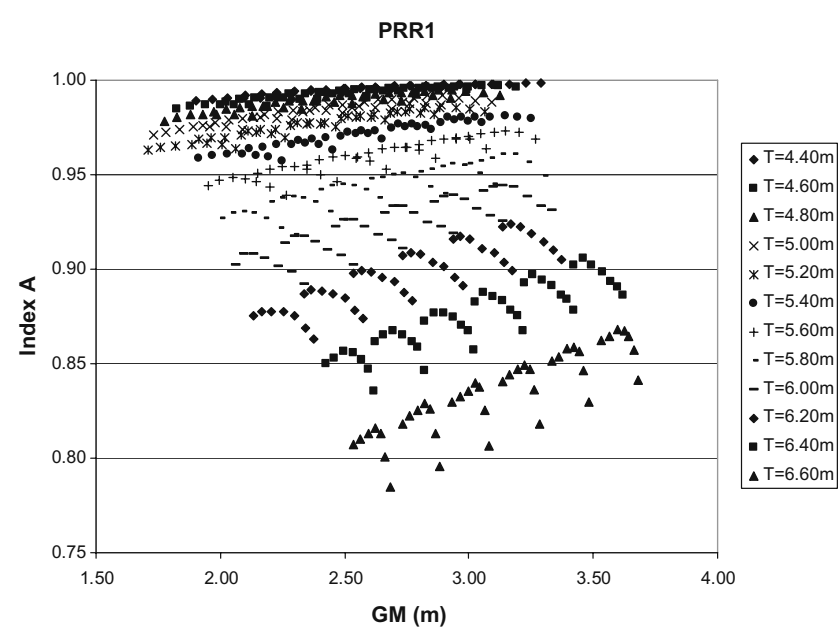

Fig. 35. Sensitivity of Index A to the metacentric height (GM) with respect to the draught

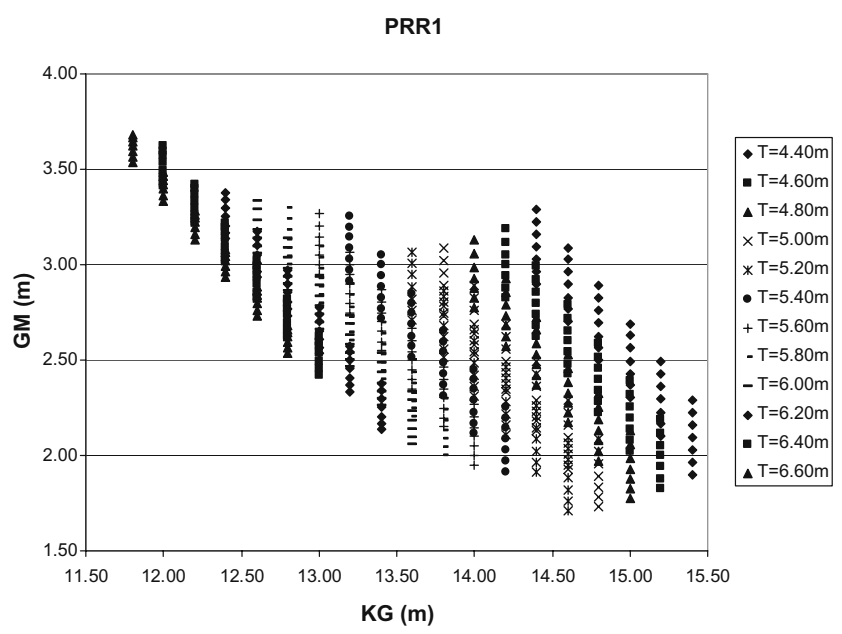

Fig. 36. Sensitivity of Index A to the centre of gravity with respect to metacentric height

which gives maximum Index A values near the even keel condition (Fig. 34).

Acknowledgments. The work reported in this article was carried out under the ROROPROB project, G3RD-CT-2000-00030, with funding from the European Commission. The opinions expressed are those of the authors and should not be construed as representing the views of the European Commission.

\section{References}

1. International Maritime Organisation (1974) Regulation on subdivision and stability of passenger ships (as an Equivalent to Part B of Chapter II of the 1974 SOLAS Convention). IMO, London (this publication contains IMO Resolutions A.265 (VIII), A.266 (VIII) and Explanatory Notes)

2. International Maritime Organisation (1990) New regulations for subdivision and damage stability for dry cargo ships built on or after 01/02/1992. Resolution MSC.19(58), May 25

3. Rusaas S, Jost AEE, Francois C (1996) A new damage stability framework based upon probabilistic methods. In: Proceedings of the International Seminar on the Safety of Passenger Ro-Ro Vessels. The Royal Institution of Naval Architects, London

4. International Maritime Organisation (2000) Development of revised SOLAS Chapter II-1 Parts A, B and B-1: Report of the Working Group on Subdivision and Damage Stability (SDS) at SLF 42 (Part 2). SLF 43/3, submitted by the Chairman of the SDS Working Group, February 18

5. HARDER Project (2000-2003) Harmonisation of rules and design rationale. EC Reference G3RD-CT-1999-00028, http:// projects.dnv.com/harder_int

6. International Maritime Organisation (2003) Development of revised SOLAS Chapter II-1 Parts A, B and B-1: Final Recommendations from the Research Project HARDER. SLF 46/3/3, submitted by Norway and United Kingdom, June 6

7. International Maritime Organisation (2004) Development of revised SOLAS Chapter II-1 Parts A, B and B-1; Report of 
the Intersessional Correspondence Group-Part 1 (Chapter II-1 Draft Text). SLF 47/3/1, submitted by Sweden and the United States, June 9

8. Pawlowski M (2004) Subdivision and damage stability of ships. EuroMTEC@work.series. Fundacja Promocji Przemyslu, Gdansk, Poland

9. Vassalos D, Pawlowski M, Turan O (1996) A theoretical investigation on the capsizal resistance of passenger Ro-Ro vessels and proposal of survival criteria. Final Report, Task
5, Joint NorthWest European R\&D Project. University of Strathclyde, Glasgow, UK

10. Vassalos D, Konovessis D (2001) Damage survivability of floating marine structures - a probabilistic approach. In: Proceedings of the Twentieth International Conference on Offshore Mechanics and Arctic Engineering (OMAE 2001). The American Society of Mechanical Engineers, Ocean, Offshore and Arctic Engineering (OOAE) Division, Rio de Janeiro, Brazil 